\title{
Comparison of static and dynamic in vitro digestion models to estimate the bioaccessibility of lutein in lutein-rich foods
}

\author{
Eun Ha Lee ${ }^{1} \cdot$ Kwang Hyun Cha ${ }^{1}$ Trang Thi Vuong ${ }^{2,3}$. \\ Sang Min Kim ${ }^{1,2} \cdot$ Cheol-Ho Pan ${ }^{1,3} \mathbb{C}_{\mathbb{C}}$
}

Received: 20 March 2018/Accepted: 28 May 2018/Published online: 12 June 2018

(C) The Korean Society for Applied Biological Chemistry 2018

\begin{abstract}
This study aimed to determine the bioaccessibility of lutein in lutein-rich food, using static and dynamic models of in vitro gastrointestinal digestion. Here, kale powder (KP) and lutein supplement (LS) were used as representative lutein-rich foods. The bioaccessibility of lutein from KP did not considerably differ between static (59.92\%) and dynamic (56.08\%) digestion. Bioaccessibility was consistently maintained at the same level during dynamic digestion. The amount of lutein released from the LS during dynamic digestion was five times higher than that released during static digestion (67.88 vs $12.34 \%)$. The results showed that (a) bioaccessibility of lutein was affected by various factors such as food source, solid:liquid ratio, and interaction with dietary components, and (b) dynamic digestion should be suitable for evaluating the bioaccessibility of lutein in high-fat foods.
\end{abstract}

Keywords Dynamic in vitro digestion - Kale powder . Lutein · Lutein bioaccessibility $\cdot$ Lutein supplement $\cdot$ Static in vitro digestion

Cheol-Ho Pan

panc@kist.re.kr

$1 \quad$ Systems Biotechnology Research Center, KIST Gangneung Institute of Natural Products, Gangneung 25451, Republic of Korea

2 Convergence Research Center for Smart Farm Solution, KIST Gangneung Institute of Natural Products, Gangneung 25451, Republic of Korea

3 Division of Bio-Medical Science and Technology, KIST School, Korea University of Science and Technology, Seoul 02792, Republic of Korea

\author{
Abbreviations \\ KP Kale powder \\ LS Lutein supplement \\ HPLC High-performance liquid chromatography \\ TBME tert-Butyl methyl ether \\ TIM TNO gastrointestinal model \\ DIDGI Dynamic gastrointestinal digester \\ ESIN Engineered stomach and small intestine
}

\section{Introduction}

Lutein, a carotenoid, is a lipophilic compound that exhibits numerous biological activities like antioxidative and antiinflammatory effects and reduces the risk of atherosclerosis and age-related macular degeneration [1-4]. Lutein is abundant in green leafy vegetables such as spinach and kale; it has to be consumed orally because it is not synthesized in the human body [5], The bioavailability of lutein is relatively low in humans; a study reported that only $0.8-2.7 \%$ of lutein was detected in human serum after the intake of spinach and collard [6].

Lutein bioavailability is affected by various factors, such as the followings: physicochemical properties; food sources; food matrix; processing; and interactions with other dietary compounds, such as fiber, lipids, and other carotenoids [7]. Lutein is released from the food matrix, transferred to lipid droplets, and incorporated into mixed bile salt micelles during digestion [8]. Many lutein supplements (LSs) have recently become available commercially in the form of tablets or capsules, and some powders prepared from green leafy vegetables like spinach and kale can also provide an equivalent amount of lutein per serving. However, only a few studies have analyzed the 
differences in the bioavailability of lutein in these luteinrich foods.

Simulated in vitro digestion models have been widely used to mimic the human gastrointestinal environment and investigate the complex influences of diverse factors on carotenoid availability. Static in vitro models use sequential exposure to simulate digestion in different compartments (mouth, stomach, and intestine) and are used to study the bioaccessibility of a great variety of nutrient compounds (carotenoids, fatty acids, vitamins, and metals) [9-12]. Dynamic in vitro models, for example, TIM-1, DIDGI, and ESIN, accurately reproduce the gradual transit of ingested compounds through the gastrointestinal tract using a multicompartment computer-controlled system that is able to provide more reliable and reproducible data that are consistent with in vivo data [13-15]. To date, only a few studies have compared the results generated by various in vitro digestion methods for several types of lutein-rich foods.

Therefore, this study aimed to compare static and simple dynamic digestion models to evaluate the bioaccessibility of lutein; two types of lutein-rich food, i.e., kale powder (KP) and LS, were used for this purpose.

\section{Materials and methods}

\section{Materials and chemicals}

To evaluate the bioaccessibility of lutein in lutein-rich foods, a commercial KP product and an LS, consisting of Calendula officinalis (marigold) flower extract with omega-3 fatty acids, were purchased from the local market. Pepsin from porcine gastric mucosa, pancreatin from porcine pancreas, bile salts, lipase from porcine pancreas, trans- $\beta$-Apo- 8 -carotenal, and high-performance liquid chromatography (HPLC)-grade tert-butyl methyl ether (TBME) were all purchased from Sigma-Aldrich (St Louis, MO, USA). All other chemicals used were of analytical grade.

\section{In vitro gastrointestinal digestion}

Static in vitro digestion was performed according to the method reported by Garrett et al. [16] with slight modifications. For dynamic digestion, the DIDGI ${ }^{\circledR}$ system, a simple two-compartment digestion system that has recently been developed by the French National Institute for Agricultural Research, was used [14]. Table 1 provides a schematic overview of the experimental conditions for the static and dynamic in vitro digestion models.

\section{Static digestion}

The samples (KP, $5 \mathrm{~g}$; LS, 1 capsule) were mixed with $80 \mathrm{~mL}$ of saline solution containing $\mathrm{NaCl}, \mathrm{KCl}$, and $\mathrm{CaCl}_{2}$ (120, 5, and $6 \mathrm{mM}$, respectively). To mimic the gastric phase of human digestion, the $\mathrm{pH}$ was reduced to 2.5 with $1 \mathrm{~N} \mathrm{HCl}$, and $4.0 \mathrm{~mL}$ of porcine pepsin solution $(0.15 \mathrm{~g} /$ $\mathrm{mL}$ saline solution) was added, leading to a final volume of $120 \mathrm{~mL}$. The samples were incubated at $37^{\circ} \mathrm{C}$ for $1 \mathrm{~h}$ in a shaking incubator at $150 \mathrm{rpm}$. To simulate the intestinal phase, the $\mathrm{pH}$ was adjusted to 6.5 with $1.0 \mathrm{M}$ sodium bicarbonate, followed by the addition of $4.0 \mathrm{~mL}$ of pancreatin $(0.2 \mathrm{~g} / \mathrm{mL}$ saline solution $), 4.0 \mathrm{~mL}$ of pancreatic lipase $(0.1 \mathrm{~g} / \mathrm{mL}$ saline solution $)$, and $10.0 \mathrm{~mL}$ of bile salts $(0.25 \mathrm{~g} / \mathrm{mL}$ in saline solution), leading to a final volume of $200 \mathrm{~mL}$. The samples were incubated for $5 \mathrm{~h}$ at $37^{\circ} \mathrm{C}$ in a shaking incubator at $150 \mathrm{rpm}$ to complete the intestinal phase of the static in vitro digestion process. During incubation, sampling was performed at 90, 120, 180, and $360 \mathrm{~min}$. Each digestate sample $(2.0 \mathrm{~mL})$ was centrifuged at $823 \mathrm{~g}$ for $10 \mathrm{~min}$ and used for lutein analysis.

\section{Dynamic digestion}

Dynamic gastrointestinal digestion was performed using a bioreactor-based digestion system consisting of two consecutive compartments mimicking the stomach and small intestine. Anaerobic conditions were maintained by purging the air with nitrogen. The flows of ingesta, $\mathrm{HCl}, \mathrm{Na}_{2}$ $\mathrm{CO}_{3}$, bile salts, enzymes, and transit for each compartment were controlled by peristaltic pumps, and the inclusion of the parameters used for analysis was based on the literature $[15,17]$. A power exponential mathematical equation for gastric and intestinal delivery was used to control the transit time of the chyme in each compartment:

$F=2\left({ }^{-t / t}{ }_{1 / 2}\right)^{\beta}$

where $F$ represents the fraction of the chyme remaining in the stomach and intestine compartments, $t$ is the time of delivery, $t_{1 / 2}$ is the half time of delivery and $\beta$ is the coefficient describing the shape of the curve, as described previously [15, 17].

After an exhaustive review of literature on human gastrointestinal physiological conditions, the parameters were fixed at $t_{1 / 2}=85$ or $250 \mathrm{~min}$ and $\beta=1.8$ or 2.5 for gastric and intestinal transit times, respectively. The gastric phase was simulated using pepsin, and $\mathrm{HCl}$ was added to lower the $\mathrm{pH}$ from 6.4 to 1.7 over a period of $12 \mathrm{~h}$. Intestinal $\mathrm{pH}$ was maintained constant at 6.5 , and porcine pancreatin, pancreatic lipase, and bile salts were added at a constant flow rate of $0.25 \mathrm{~mL} / \mathrm{min}$. Samples were collected from the 
Table 1 Overview of the parameters for the static and dynamic in vitro digestion models

\begin{tabular}{|c|c|c|}
\hline & Static digestion & Dynamic digestion \\
\hline Incubation temperature & $37^{\circ} \mathrm{C}$ & $37^{\circ} \mathrm{C}$ \\
\hline Agitation & $150 \mathrm{rpm}$ & $150 \mathrm{rpm}$ \\
\hline \multicolumn{3}{|l|}{ Gastric digestion } \\
\hline Volume & $120 \mathrm{~mL}$ & $400 \mathrm{~mL}$ (ingested), $80 \mathrm{~mL}$ (fasted) \\
\hline $\mathrm{pH}$ & $2.0-2.5$ & $\begin{array}{l}\text { Time }=0 \mathrm{~min}, \mathrm{pH}=6.4 \\
\text { Time }=15 \mathrm{~min}, \mathrm{pH}=5.7 \\
\text { Time }=45 \mathrm{~min}, \mathrm{pH}=4.5 \\
\text { Time }=90 \mathrm{~min}, \mathrm{pH}=2.9 \\
\text { Time }=120 \mathrm{~min}, \mathrm{pH}=2.3 \\
\text { Time }=300 \mathrm{~min}, \mathrm{pH}=1.7\end{array}$ \\
\hline Incubation time & $1 \mathrm{~h}$ & $\begin{array}{l}t_{1 / 2}=85 \mathrm{~min} \\
\beta=1.8\end{array}$ \\
\hline Gastric materials & Pepsin (300 KU) & Pepsin $(2000 \mathrm{U} / \mathrm{mL}, 0.25 \mathrm{~mL} / \mathrm{min})$ \\
\hline \multicolumn{3}{|l|}{ Intestinal digestion } \\
\hline Volume & $200 \mathrm{~mL}$ & $30 \mathrm{~mL}$ of bile salts, pancreatin, and pancreatic lipase mixture solution \\
\hline $\mathrm{pH}$ & 6.5 & 6.5 \\
\hline Incubation time & $5 \mathrm{~h}$ & $\begin{array}{l}t_{1 / 2}=250 \mathrm{~min} \\
\beta=2.5\end{array}$ \\
\hline Intestinal materials & Pancreatin $(3.2 \mathrm{KU})$ & Pancreatin $(200 \mathrm{U} / \mathrm{mL}, 0.25 \mathrm{~mL} / \mathrm{min})$ \\
\hline & Pancreatic lipase (800 U) & Pancreatic lipase $(50 \mathrm{U} / \mathrm{mL}, 0.25 \mathrm{~mL} / \mathrm{min})$ \\
\hline & Bile salts $(2.5 \mathrm{~g})$ & Bile salts $(20 \mathrm{mg} / \mathrm{mL}, 0.25 \mathrm{~mL} / \mathrm{min})$ \\
\hline
\end{tabular}

intestinal effluents over a period of $12 \mathrm{~h}$ after ingestion and used for further analysis.

\section{Lutein analysis}

Each sample was added to $4 \mathrm{~mL}$ methanol and $0.5 \mathrm{~mL}$ trans- $\beta$-Apo- 8 -carotenal (internal standard; $2 \mu \mathrm{g} / \mathrm{mL}$ ). Then, it was saponified by incubation with $0.5 \mathrm{~mL}$ of $5 \mathrm{M}$ $\mathrm{KOH}$ at $60{ }^{\circ} \mathrm{C}$ for $10 \mathrm{~min}$. To extract lutein, $4.5 \mathrm{~mL}$ of $n$ hexane was added, and the mixture was vortexed for $30 \mathrm{~s}$ and mixed with $9 \mathrm{~mL}$ water; it was then centrifuged at $823 g$ for $10 \mathrm{~min}$ to accelerate phase separation. The upper layer was collected and dried using a speed vacuum dryer (SPD1010, Thermo Scientific, Waltham, MA, USA). The collected fraction was resolubilized in methanol:TBME (90:10) solution.

\section{HPLC analysis}

Lutein analysis was performed using an ultimate 3000 HPLC system (Dionex, Germering, Germany) consisting of an auto sampler, pump, and spectrometer. Chromatographic separation was carried out on a YMC carotenoid column $(150 \times 4.6 \mathrm{~mm} ; 3 \mu \mathrm{m}$ particle size) (YMC Co., Kyoto, Japan) at $35^{\circ} \mathrm{C}$ with an injection volume of $10 \mu \mathrm{L}$ and monitored at $450 \mathrm{~nm}$ for lutein detection. Gradient elution was performed with methanol:TBME (10:90) as solvent A and water:methanol (5:95) as solvent B, and the flow rate was maintained at $1.0 \mathrm{~mL} / \mathrm{min}$. Subsequently, the following gradient was used; initially, $10 \%$ solvent A was used for $3 \mathrm{~min}$, which was changed to $20 \%$ solvent $\mathrm{A}$ for $17 \mathrm{~min}$, held for $10 \mathrm{~min}$, and changed to $70 \%$ solvent $\mathrm{A}$ for 4 min. The column was equilibrated with $10 \%$ solvent $\mathrm{A}$ for $15 \mathrm{~min}$ before each injection. Lutein was identified and quantified by comparing the retention time, spectral profile, and peak area with those of pure standard (Carbosynth Limited, Berkshire, UK). Lutein bioaccessibility was defined as the fraction of lutein that was released from its food matrix within the gastrointestinal tract and thus became available for intestinal absorption.

\section{Fat analysis}

Fat was extracted from samples of lutein-rich foods using the Rose-Gottlieb method with slight modifications [18]. Two grams of each sample was weighed accurately in flasks; subsequently, $2 \mathrm{~mL}$ of ethanol and $10 \mathrm{~mL}$ of hydrochloric acid solution were added. The mixture was heated in a water bath for $40 \mathrm{~min}$ and then transferred to a Mojonnier tube into which $10 \mathrm{~mL}$ of ethanol was 
subsequently added. Next, $25 \mathrm{~mL}$ of ether was added and the mixture was shaken; this was followed by the addition of $25 \mathrm{~mL}$ of petroleum ether. The mixture was shaken again and left to stand until the ether layer completely separated and then the ether layer is a transferred to an evaporation flask. The solvent was removed by a rotary evaporator under vacuum, leaving the extracted fat in the evaporation flask.

\section{Statistical analysis}

A minimum of three individual digestions were performed for statistical analysis. All data are expressed as mean \pm the standard error of the mean. Statistical comparisons between groups were performed using Student's $t$ test with GraphPad Prism version 5.

\section{Results and discussion}

\section{Lutein and fat content in KP and the LS}

To evaluate the bioaccessibility of lutein in different foods, KP and an LS were selected and used for both static and dynamic in vitro digestion. HPLC coupled with DAD was used for the lutein determination. In our samples, lutein appeared to be the main peak both KP and LS (Fig. 1). Table 2 shows the mean daily intake and the fat and lutein content of KP and the LS. The amount of lutein per unit mass in the LS was approximately three times higher than that in KP. Recommended daily intake of KP ( $15 \mathrm{~g}$ per day) is three times higher than LS (4.48 $\mathrm{g}$ per day) but lutein content of KP is similar to LS (3000 $\mu$ g per day). One of the main differences between KP and the LS was the fat content. The fat content of the LS was approximately 10 times higher than that of KP, which was even more than half of the daily intake of LS ( $>2 \mathrm{~g}$ per day). This indicates that humans consume high amounts of fat because of intake of supplements to improve health.

Since the bioaccessibility of lutein is quite low, LSs generally contain oils such as omega-3 fatty acids. Some studies have shown that intake of lutein along with a highfat diet affects the increase in the plasma concentration of lutein $[19,20]$. Kale is widely recognized as a good source for lutein supplementation because it contains high levels of unesterified lutein and the bioaccessibility of lutein from kale is known to be not bad (35-60\%) [21]. In the current study, the lutein content of KP was considerably similar to that of LS, showing that KP could serve as an alternative for lutein replenishment.

\section{Bioaccessibility of lutein in KP and the LS during static digestion}

For static digestion, $5 \mathrm{~g}$ of $\mathrm{KP}$ and one tablet of the $\mathrm{LS}$ were used to obtain similar lutein content $(770-930 \mu \mathrm{g})$. Information regarding the bioaccessibility of lutein from $\mathrm{KP}$ and the LS is provided in Fig. 1. During the initial digestion process, very little lutein was released from both KP and LS, showing that digestion in the stomach was not the key step for lutein micellarization. However, lutein from KP started getting micellarized during the small intestinal phase and the maximum micellarization was achieved at $120 \mathrm{~min}(59.92 \%)$. A notable finding is that the bioaccessibility showed a slight decline to $14.45 \%$ from 120 to $360 \mathrm{~min}$. Interestingly, the bioaccessibility of lutein in the LS was relatively lower than that of lutein from KP in static simulated digestion, and the maximum bioaccessibility was just $12.34 \%$ at $120 \mathrm{~min}$.

Various factors such as $\mathrm{pH}$, enzyme concentrations, digestion times, and the solid/liquid ratio might influence the bioaccessibility results obtained for in vitro digestion [22]. In the current study, the bioaccessibility for lutein in KP was approximately $60 \%$, which is similar to the results of another study using dark leafy vegetables [21]. However, the bioaccessibility in the case of the LS was quite low, which might be due to the limitation of the static digestion method. The static model just underwent batch process of digestive enzymes and bile salts, whereas fresh enzyme and digestive fluid are continuously secreted and supplied from the host in real digestive conditions. Moreover, the LS contained a substantial amount of fat in the capsule, which might be one of the factors hindering the formation of a suitable lutein emulsion, Other studies have reported that the fat content and type are important factors involved in decreasing the bioavailability of lipophilic compounds like carotenoids [21, 23, 24]. Carotenoid bioaccessibility has generally been found to be proportional to the amount of fat $(0-8 \%)$ added to the food materials when other factors such as the enzyme and bile salt concentrations remained constant [21]. These previous findings are not in agreement with our result that lutein in the LS had poor bioaccessibility as compared to that from $\mathrm{KP}$; this difference might be due to the fat content of the LS, which is too high ( $>50 \%$ ) for formation of a proper emulsion in the static digestion model. A study reported that the micellarization efficiency of lutein from an LS was approximately $80 \%$ with the static digestion method; however, this can be considered a different case from our study because that supplement was pre-emulsified and diluted using skim milk [25]. 

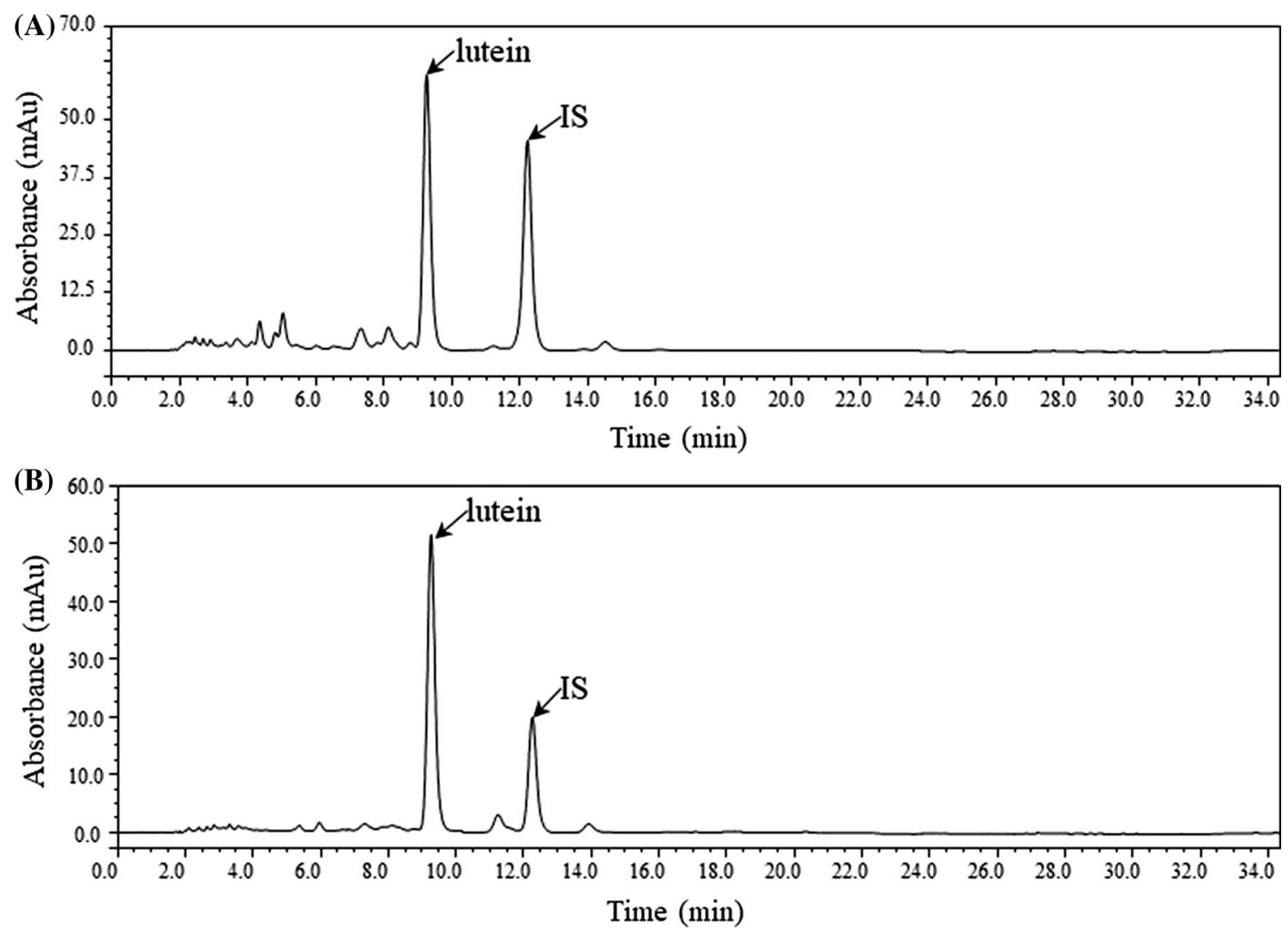

Fig. 1 HPLC chromatogram of KP (A) and LS (B) at $450 \mathrm{~nm}$. IS internal standards, trans- $\beta$-Apo-8'-carotenal

Table 2 Fat and lutein content of the lutein-rich foods

\begin{tabular}{llrr}
\hline & Mean daily intake & Fat $(\mathrm{g} / 100 \mathrm{~g})$ & Lutein $(\mu \mathrm{g} / \mathrm{g})$ \\
\hline KP (kale powder) & $5-15 \mathrm{~g}$ & $5.9 \pm 0.14$ & $186.04 \pm 12.03$ \\
LS (lutein supplement) & 4 capsules $(4.48 \mathrm{~g})$ & $54.7 \pm 0.57$ & $686.92 \pm 21.87$ \\
\hline
\end{tabular}

The results were expressed as mean \pm standard deviation $(n=3)$

\section{Bioaccessibility of lutein in KP and the LS during dynamic digestion}

The DIDGI-based dynamic in vitro digestion system, which is composed of two compartments for the stomach and small intestine, was used to estimate lutein bioaccessibility under conditions that were more similar to actual in vivo conditions. The lutein bioaccessibility results with this method showed a different pattern as compared to that for static digestion (Fig. 2). The bioaccessibility in the case of KP was more than $50 \%$, which was not considerably different from the results of static in vitro digestion; however, almost two times longer digestion time was required to achieve maximum bioaccessibility. In the case of KP, lutein bioaccessibility slightly decreased during long-term static digestion; however, it remained constant during dynamic digestion. The bioaccessibility dramatically increased during dynamic in vitro digestion for the

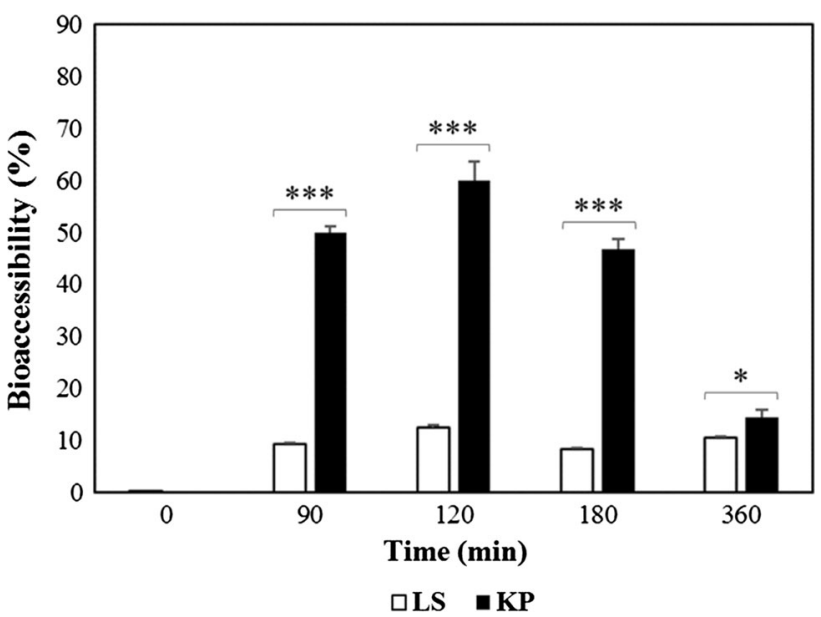

Fig. 2 Lutein bioaccessibility of KP and LS after applying the static digestion method. Values marked with an asterisk indicate significant differences between KP and LS groups. $* P<0.05$, $* * P<0.01$, and $* * * P<0.001(n=3)$ 
LS; the maximum value was $67.88 \%$, which was five times higher than that for static digestion. Furthermore, in contrast to the findings for static digestion, bioaccessibility for the LS was greater than that for KP during dynamic digestion. The lutein bioaccessibility for the LS slowly increased and remained consistent, similar to that for KP.

Although the static in vitro digestion model is simple and cost-effective to operate several experimental variables, the model mostly maintains the initial conditions at each digestion step and cannot mimic physiological conditions, including gastric emptying, peristaltic movements, transit times for each digestion stage, dynamic $\mathrm{pH}$ changes, and secretion rates of digestive enzymes [26, 27]. Using dynamic digestion, it is possible to simulate more exact digestion conditions that are similar to those of in vivo digestion. The two-compartment dynamic system used in the current study has several advantages with respect to reproducing the dynamic gastric and intestinal transit times, the kinetics of gastric $\mathrm{pH}$, and the secretion of digestive fluid in the stomach and small intestine regions. Interestingly, the low lutein bioaccessibility from LS using the static method considerably upsurged when dynamic digestion was applied. In contrast to the static digestion method, dynamic digestion enabled a consistent supply of new digestive enzymes, even though their concentration was lower than that obtained with static digestion (Table 1). In addition, with dynamic digestion, the reaction volume and transit time of the digestate could be controlled both in the gastric and intestinal compartments, as per a power exponential mathematical equation (Fig. 3).

The interfacial area of colloids is an important factor for lipophilic compounds to form an emulsion, which is a prerequisite process for micellarization of hydrophobic components and for reaction with several digestive

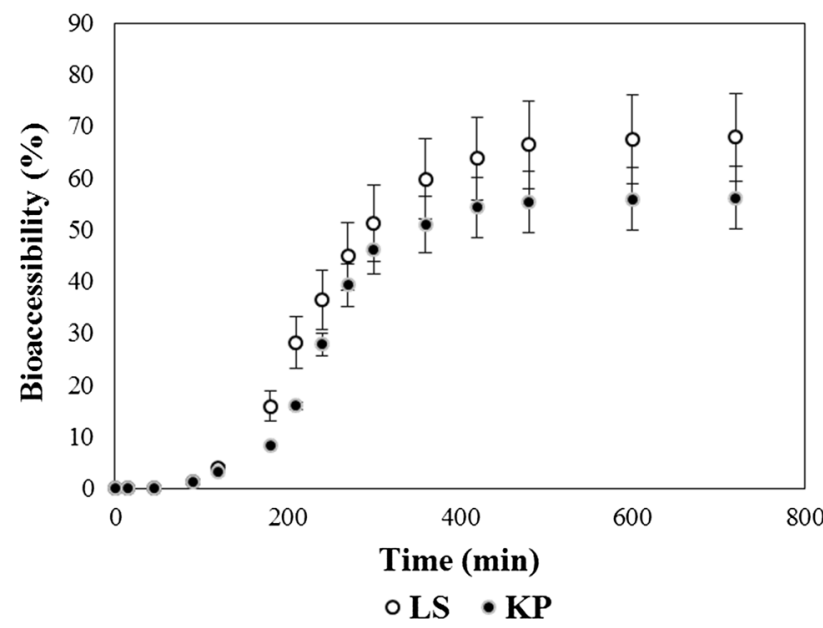

Fig. 3 Lutein bioaccessibility of KP and LS after applying the dynamic digestion method. Values represented mean \pm SD of three independent experiments enzymes [28]. In the dynamic digestion system, the reaction volume can be modulated by controlling the transit time. Therefore, it seems that, in this system, a sustainable reaction was induced between food materials and fresh digestive components, thereby improving the sensitivity of the digestion process by increase in interfacial area. These might be the reasons for the dynamic digestion to increase the lutein bioaccessibility from LS with high fat (>50\%) during dynamic digestion. The KP and LS samples (at the amounts utilized) used for digestion were found to have similar lutein content, but the bioaccessibility of lutein in KP was slightly lower than that for LS. This trend might be attributable to the indigestible cell wall components such as dietary fibers in KP, which are known to inhibit the digestion of carotenoids by forming chemical complexes with food materials and inactivating digestive enzymes. Previous research has shown that the bioaccessible lutein content of leafy vegetables decreases with increase in the pectin content. Nevertheless, as the difference in lutein bioaccessibility was not statistically significant and KP had not only almost equivalent efficiency for lutein micellarization but also relatively low fat content as compared to the LS, KP can be a valuable alternative for lutein supplementation.

The bioaccessibility of lutein in lutein-rich food was analyzed using the static and dynamic models for in vitro digestion. In the case of LS, the bioaccessibility was much higher during dynamic digestion and remained at a consistent level during this process. The bioaccessibility was affected by the food source and dietary composition, notably the fat concentration, in this study. Furthermore, with dynamic digestion, it is possible to emulate in vivo digestion. Thus, this method is suitable for evaluating the bioaccessibility of lutein in high-fat foods.

Acknowledgments This work was supported by a KIST intramural research grant (2Z05310).

\section{Compliance with ethical standards}

Conflict of interest The authors declare no competing financial interest.

\section{References}

1. Dwyer JH, Navab M, Dwyer KM, Hassan K, Sun P, Shircore A, Hama-Levy S, Hough G, Wang X, Drake T, Merz CN, Fogelman AM (2001) Oxygenated carotenoid lutein and progression of early atherosclerosis: the Los Angeles atherosclerosis study. Circulation 103:2922-2927

2. Kim JH, Na HJ, Kim CK, Kim JY, Ha KS, Lee HS, Chung HT, Kwon HJ, Kwon YG, Kim YM (2008) The non-provitamin A carotenoid, lutein, inhibits NF-kB-dependent gene expression through redox-based regulation of the phosphatidylinositol 
3-kinase/PTEN/Akt and NF-kB-inducing kinase pathways: role of $\mathrm{H}_{2} \mathrm{O}_{2}$ in NF-kB activation. Free Radic Biol Med 45:885-896

3. Seddon JM, Ajani UA, Sperduto RD, Hiller R, Blair N, Burton TC, Farber MD, Gragoudas ES, Haller J, Miller DT, Yannuzzi LA, Willett W (1994) Dietary carotenoids, vitamins A, C, and E, and advanced age-related macular degeneration. JAMA 272:1413-1420

4. Zou Z, Xu X, Huang Y, Xiao X, Ma L, Sun T, Dong P, Wang X, Lin $X$ (2011) High serum level of lutein may be protective against early atherosclerosis: the Beijing atherosclerosis study. Atherosclerosis 219:789-793

5. Roberts RL, Green J, Lewis B (2009) Lutein and zeaxanthin in eye and skin health. Clin Dermatol 27:195-201

6. Lienau A, Glaser T, Tang G, Dolnikowski GG, Grusak MA, Albert K (2003) Bioavailability of lutein in humans from intrinsically labeled vegetables determined by LC-APCI-MS. J Nutr Biochem 14:663-670

7. Failla ML, Huo T, Thakkar SK (2008) In vitro screening of relative bioaccessibility of carotenoids from foods. Asia Pac J Clin Nutr 17(Suppl 1):200-203

8. Yonekura L, Nagao A (2007) Intestinal absorption of dietary carotenoids. Mol Nutr Food Res 51:107-115

9. Granado-Lorencio F, Herrero-Barbudo C, Acién-Fernández G, Molina-Grima E, Fernández-Sevilla JM, Pérez-Sacristán B, Blanco-Navarro I (2009) In vitro bioaccesibility of lutein and zeaxanthin from the microalgae Scenedesmus almeriensis. Food Chem 114:747-752

10. Metian M, Charbonnier L, Oberhaënsli F, Bustamante P, Jeffree R, Amiard J-C, Warnau M (2009) Assessment of metal, metalloid, and radionuclide bioaccessibility from mussels to human consumers, using centrifugation and simulated digestion methods coupled with radiotracer techniques. Ecotoxicol Environ Saf 72:1499-1502

11. O'Sullivan L, Jiwan MA, Daly T, O'Brien NM, Aherne SA (2010) Bioaccessibility, uptake, and transport of carotenoids from peppers (Capsicum spp.) using the coupled in vitro digestion and human intestinal Caco-2 cell model. J Agric Food Chem 58:5374-5379

12. Thakkar SK, Maziya-Dixon B, Dixon AGO, Failla ML (2007) $\beta$ Carotene micellarization during in vitro digestion and uptake by Caco- 2 cells Is directly proportional to $\beta$-carotene content in different genotypes of cassava. J Nutr 137:2229-2233

13. Guerra A, Denis S, le Goff O, Sicardi V, François O, Yao A-F, Garrait G, Manzi AP, Beyssac E, Alric M, Blanquet-Diot S (2016) Development and validation of a new dynamic computercontrolled model of the human stomach and small intestine. Biotechnol Bioeng 113:1325-1335

14. Ménard O, Cattenoz T, Guillemin H, Souchon I, Deglaire A, Dupont D, Picque D (2014) Validation of a new in vitro dynamic system to simulate infant digestion. Food Chem 145:1039-1045
15. Minekus M, Marteau P, Havenaar R, Huisin’t Veld JHH (1995) Multicompartmental dynamic computer-controlled model simulating the stomach and small intestine. Atla-Altern Lab Anim 23:197-209

16. Garrett DA, Failla ML, Sarama RJ (1999) Development of an in vitro digestion method to assess carotenoid bioavailability from meals. J Agric Food Chem 47:4301-4309

17. Blanquet-Diot S, Soufi M, Rambeau M, Rock E, Alric M (2009) Digestive stability of xanthophylls exceeds that of carotenes as studied in a dynamic in vitro gastrointestinal system. J Nutr 139:876-883

18. James CS (2012) Analytical chemistry of foods. Springer, Boston

19. Riso P, Klimis-Zacas D, Del Bo C, Martini D, Campolo J, Vendrame S, Møller P, Loft S, De Maria R, Porrini M (2013) Effect of a wild blueberry (Vaccinium angustifolium) drink intervention on markers of oxidative stress, inflammation and endothelial function in humans with cardiovascular risk factors. Eur J Nutr 52:949-961

20. Roodenburg AJC, Leenen R, van het Hof KH, Weststrate JA, Tijburg LBM (2000) Amount of fat in the diet affects bioavailability of lutein esters but not of a-carotene, b-carotene, and vitamin E in humans. Am J Clin Nutr 71:1187-1193

21. Failla ML, Chitchumronchokchai C, Ferruzzi MG, Goltz SR, Campbell WW (2014) Unsaturated fatty acids promote bioaccessibility and basolateral secretion of carotenoids and alphatocopherol by Caco-2 cells. Food Funct 5:1101-1112

22. Waisberg M, Black WD, Waisberg CM, Hale B (2004) The effect of $\mathrm{pH}$, time and dietary source of cadmium on the bioaccessibility and adsorption of cadmium to/from lettuce (Lactuca sativa L. cv. Ostinata). Food Chem Toxicol 42:835-842

23. Nagao A, Kotake-Nara E, Hase M (2013) Effects of fats and oils on the bioaccessibility of carotenoids and vitamin e in vegetables. Biosci Biotechnol Biochem 77:1055-1060

24. Xavier AAO, Mercadante AZ, Garrido-Fernández J, Pérez-Gálvez A (2014) Fat content affects bioaccessibility and efficiency of enzymatic hydrolysis of lutein esters added to milk and yogurt. Food Res Int 65:171-176

25. Chitchumroonchokchai C, Schwartz SJ, Failla ML (2004) Assessment of lutein bioavailability from meals and a supplement using simulated digestion and Caco-2 human intestinal cells. J Nutr 134:2280-2286

26. Fernández-García E, Carvajal-Lérida I, Pérez-Gálvez A (2009) In vitro bioaccessibility assessment as a prediction tool of nutritional efficiency. Nutr Res 29:751-760

27. Wickham M, Faulks R, Mills C (2009) In vitro digestion methods for assessing the effect of food structure on allergen breakdown. Mol Nutr Food Res 53:952-958

28. Myers D (1999) Surfaces, interfaces and colloids. Wiley, New York 